www.jmscr.igmpublication.org

Index Copernicus Value: 79.54

ISSN (e)-2347-176x ISSN (p) 2455-0450

crossref DOI: https://dx.doi.org/10.18535/jmscr/v7i4.62

Journal Of Medical Science And Clinical Research

IGM Publication

An official Publication of IGM Publication

\title{
Brain CT scans findings in Eclampsia mothers and its clinical evaluation: A cross sectional study
}

\section{Authors
Dr Anjan Dasgupta ${ }^{1}$, Dr Suman Kumar Biswas ${ }^{2 *}$, Prof. Swapan Kumar Jana ${ }^{3}$, Dr Debabrata Nandy ${ }^{4}$

${ }^{1}$ Associate Professor, G \& O, ${ }^{2} \mathrm{MS}$ (G\&O), Senior Resident, ${ }^{3}$ Professor, G \& O., ${ }^{4}$ Associate Professor, Radio Diagnosis Midnapore Medical College, WB India

*Corresponding Author

Dr Suman Kumar Biswas

\begin{abstract}
Eclampsia, the sudden occurrence of tonic-clonic seizure and/ or coma without previous neurological disorder is a life threatening complications of pregnancy. The exact cause is still ill understood and recent studies using computed tomography (CT scan) and MRI helped to better understand the neuro-imaging findings and their correlation with various neurological symptoms in eclampsia.

Aims \& Objectives: The objective of the study is to evaluate the characteristics of different neurological findings and changes observe in brain through CT scan in eclampsia mothers, so that early intervention in pathological brain lesion may help to reduce maternal and perinatal morbidity and mortality.

Materials \& Methods: It was a hospital based cross sectional study with ethical approval. Eclampsia mothers who were admitted in indoor during one year were included $(n=69)$ with relevant history taking, examination, essential investigations including CT scan of the brain and results were analyzed at the end of the study. CT scans were done preferably within 72 hours of first convulsion. Those patients who were hypertensive before pregnancy or known epileptic were excluded. The MgSo4 regime and antihypertensive were used accordingly as per book teaching.

Result \& Analysis: A total of 69 eclampsia mothers were studied and CT scan of brain was performed earliest possible; Maximum number of mothers was in the age group of 17-20 years. The mean systolic and diastolic blood pressure was $166+/-14 \mathrm{mmHg}$ and $106+/-11 \mathrm{mmHg}$ respectively. CT scan findings showed that almost $50 \%$ of patient had brain edema, 17.4\% with ischemia, few with hemorrhage, hematoma and granuloma; $17.4 \%$ had no brain lesion. Those mothers who attended antenatal clinic regularly has comparatively less pathological brain lesion than who did not ( $p$ value 0.048). Patient who has visual disturbances, CT scan showed more parietal lobe involvement than any other area of brain ( $p$ value 0.017). Regarding levels of consciousness, CT scan finding has shown that pathological brain lesion has found to be more in semiconscious and unconscious group ( $p$ value 0.028). Those who have severe neurological impairment with GCS (Glasgow Coma Scale) score 0-8, CT scan showed pathological brain lesion in them ( $p$ value 0.001). It is interesting to note that, mothers who required extra dose of MgSo4 to control convulsions, CT scan also showed pathological brain lesions in them ( $p$ value 0.024).

Conclusion: Application of CT scan can be a preferred way to diagnose and detect other coexisting brain lesion in eclampsia mothers and thus could be helpful in reducing maternal and perinatal mortality.

Keywords: CT scan, Brain lesion, Eclampsia.
\end{abstract}




\section{Introduction}

Eclampsia is defined as sudden occurrence of generalized tonic-clonic seizures and or coma, not due to other neurological disorder (like epilepsy) in a pregnant woman, may or may not be associated with preeclampsia. In fact studies have found that about $40 \%$ of women with eclampsia have seizures at normal blood pressure and without proteinuria ${ }^{1}$. The neurological manifestations of eclampsia include headache, confusion, hyperreflexia, visual hallucinations and blindness in association with convulsions or coma and remain a significant life threatening complication of pregnancy. In India, the incidence ranges from 1 in 500 to 1 in 30 and maternal mortality (2-30\%) and perinatal mortality (30-50) is very high $^{2}$. Recent studies using computerized tomography (CT scan) and magnetic resonance imaging (MRI) helped to better understand the brain lesions that may occur during eclampsia ${ }^{3}$. Regarding the underlying mechanism for neurological symptoms, various hypotheses have postulated. One concept is that, the cerebral circulation is in a state of over-auto regulation in response to elevated cerebral perfusion pressure in preeclampsia which causes ischemia based on brain imaging and this ischemic brain injury causes seizure and reversible in nature ${ }^{1}$.The second hypothesis represents a form of hypertensive encephalopathy in which a rapid rise of blood pressure overcomes the myogenic vasoconstriction of cerebral arteries and arterioles causing loss of auto regulatory capacity and blood brain barrier disruption that promotes vasogenic oedema ${ }^{1,4}$. All neurological changes have been comparable in both the cases by neuro-imaging findings of CT and MRI

\section{Aims \& Objectives}

To minimize the maternal death in eclampsia mothers, various neuro-imaging modalities have applied to evaluate the extent and severity of brain involvement so that early interventions may be exercised in coexisting pathological brain lesions.
The objectives of the study are to evaluate 1) Characteristics of different neurological findings 2) Different changes observe through brain computed tomography (CT) scans in eclampsia mothers.

\section{Materials and Methods}

The present study is a hospital based study, cross sectional in nature and carried out for a period of one year only after approval by institutional ethics committee in a peripheral medical college of West Bengal, India. The study populations includes all eclampsia mothers who are newly admitted or already admitted in indoor including ante partum, intrapartum or postpartum period in the department of G\&O. The study period was in 2015-16 session for one year, sample size $69(\mathrm{~N}=69)$.

Inclusion criteria includes: 1) At least one episode of seizure with more than 20 weeks of gestation or less than 6 weeks of postpartum. 2) Blood pressure equal to or more than $140 \mathrm{~mm}$ of $\mathrm{Hg}$ in systolic and equal to or more than $90 \mathrm{~mm}$ of $\mathrm{Hg}$ in diastolic. 3) Urine for albumin (protein) should be at least one plus (+) by Dipstick test with or without edema.

Exclusion criteria includes: 1) Patients who are not interested to participate in the study 2) Hypertensive from the early pregnancy (before 20 weeks). 3) Known history of epilepsy or convulsion. 4) Known psychiatric or functional disorders. 5) Having known pathological intracranial lesion (SOL). 6) History of intracranial infection like meningitis, encephalitis, cerebral malaria, trauma etc.

Study Tools include BHT, Ward register book, LR register book, OT register book, detailed history taking, thorough clinical examination of the patient, bedside test for urinary protein, laboratory investigation report, USG for fetal profile, treatment record and Radiological investigation report. The entire eligible mothers were included with available investigations report including CT scan of the brain and the result were analyzed at the end of the study. Delivery status of mothers and different characteristics of CT findings on 
neurological changes were studied within the study period. Preferably CT scan was performed within 72 hours of first convulsion after stabilize the patient and after delivery was over. 16 slice GE CT scan machine was used for this imaging purpose.

The treatment of eclampsia and associated seizure activity includes magnesium sulphate injection, with initial intravenous bolus dose followed by a maintenance dose of deep intramuscular injection until 24 hours following delivery or last seizure. In our setup, we used labetalol for management of severe hypertension in addition to other supportive care.

Regarding sample size, it has been found that most previous studies conducted on neuro-radiologic aspects of eclampsia have had small sample sizes. Additionally, as previous studies that correlate various clinical and laboratory parameters with abnormalities on neuro-imaging in eclampsia ${ }^{5,6}$, our study was conducted as per available sample size $(n=69)$.

After routine laboratory investigation as per requirements and radiological findings (Brain CT scan), data were collected, gathered, tabulated and were analyzed by applying appropriate statistical methods by Epi-info Microsoft excel software. The qualitative data were expressed in terms of number and percentage. The association between different groups was assessed by means of Chi-square test. In all purpose, $\mathrm{p}$-value $<0.05$ will considered to be statistically significant.

\section{Results and Analysis}

In our study group ( $\mathrm{n}=69)$, majority of pregnancy $(57=82.61 \%)$ was in the age group between 17-20 years. According to the gravida, $81.16 \%(56 / 69)$ were primigravida (Fig-1) and as per episodes of eclampsia in different gestational age, $17.39 \%$ (12/69) had the occurrence within pregnancy up to 32 weeks, 28.99\% (20/69) between 33-36 weeks, $40.58 \%$ (28/69) 37 weeks+ and $13.03 \%$ (9/69) had postpartum eclampsia. All the patients in the study group had detectable proteinuria with a maximum number of 2+proteinuria in $47.83 \%$ (Fig-2). Maximum number of mother were delivered by caesarian section $[73.6 \%$ (51/69)], rest through the vaginal route [26.1\%( 18/69)].

According to CT scan finding of brain lesion, 17.4 $\%(12 / 69)$ had without any lesion, 50.7\% (35/69) with edema, $17.4 \%$ (12/69) with ischemia, 5.8\% (4/69) with hemorrhage, $7.2 \% \quad(5 / 69)$ with granuloma and $1.4 \%$ (1/69) with hematoma (Fig 3). As per CT scan findings, the area wise involvement of brain lesion showed $15.9 \%$ (11/69) had parietal, $20.3 \%$ (14/69) occipito-parietal, $7.2 \%$ (5/69) frontal, $14.5 \%$ (10/69) parieto-frontal, all lobe involvement in $24.6 \%$ (17/69) and $17.4 \%$ (12/69) had without any pathological brain lesion (Fig-4).

In our study, vision abnormality maximally noted in occipito-parietal lobe and those with all lobe involvement. Near about $67.8 \%$ of patient having occipito-parietal lobe involvement and if we consider involvement of parietal lobe as a whole, it is about $85.6 \%$. Here p-value is 0.017 which is statistically significant (Table no-2).

Regarding the type of eclampsia in relation with CT scan findings, only $4.3 \%$ (2/47) of ante partum eclampsia showed normal CT scan finding whereas it was reverse during intrapartum $46.1 \%(6 / 13)$ and postpartum $44.4 \%(4 / 9)$ eclampsia. In postpartum period, $22.2 \%$ (2/9) showing hemorrhage and $11.1 \%$ (1/9) were showing granuloma. Here, pvalue is 0.003 which is statistically highly significant (Table no 3 ). 
Figure: 1 Distribution of study group according to gravida. $(n=69)$.

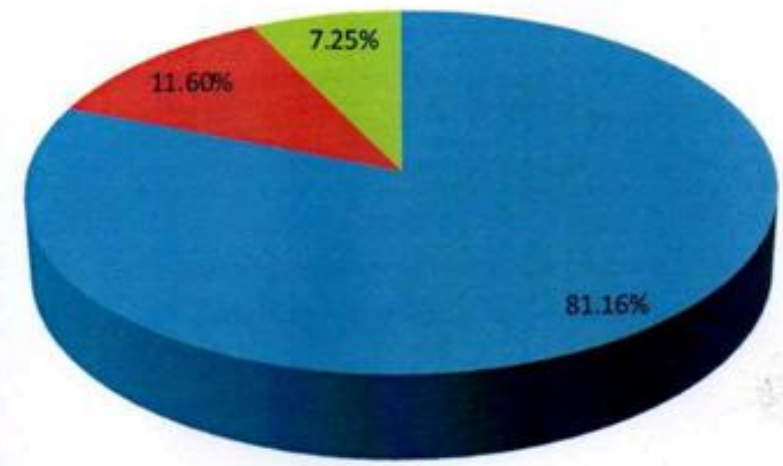

GRAVDA: $1=56$

= GRAVIDA: $2=8$

$=$ GRAVIDA: 3 \& ABOVE $=5$

Pie diagram showing primigravida were $81.16 \%$ of the study population, second gravida were $11.60 \%$ (8/69) and third gravid and above were $7.25 \%$ (5/69).

Figure: 2 Distribution of study group according to proteinuria (Dipstick test) $(n=69)$.

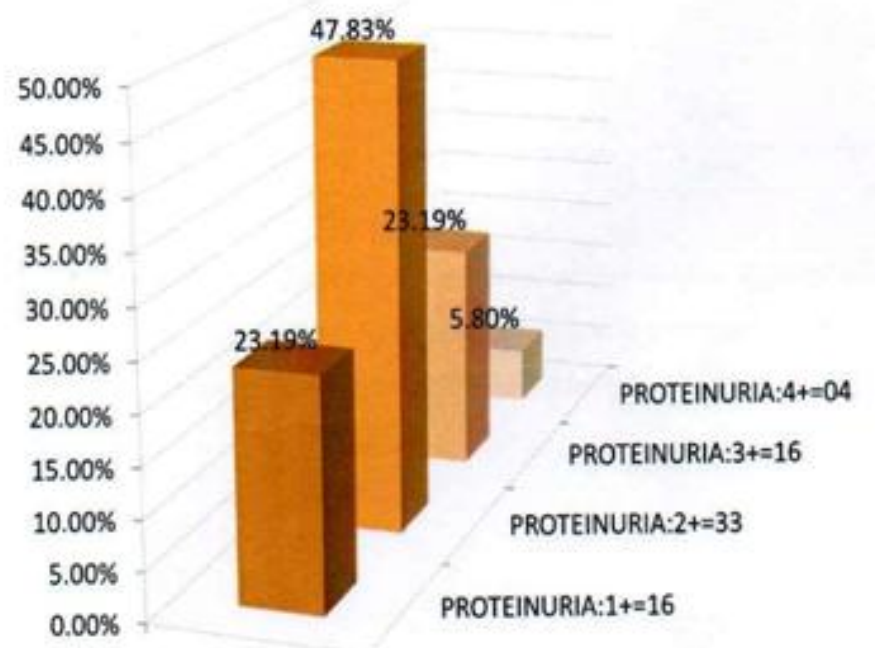

Figure shows patients with $2+$ proteinuria found to be maximum [47.83\% (33/69)] and patients with $4+$ proteinuria was minimum [5.80\%(4/69)] among the study group.
Figure: 3 Distribution of study group according to CT scan findings $(n=69)$

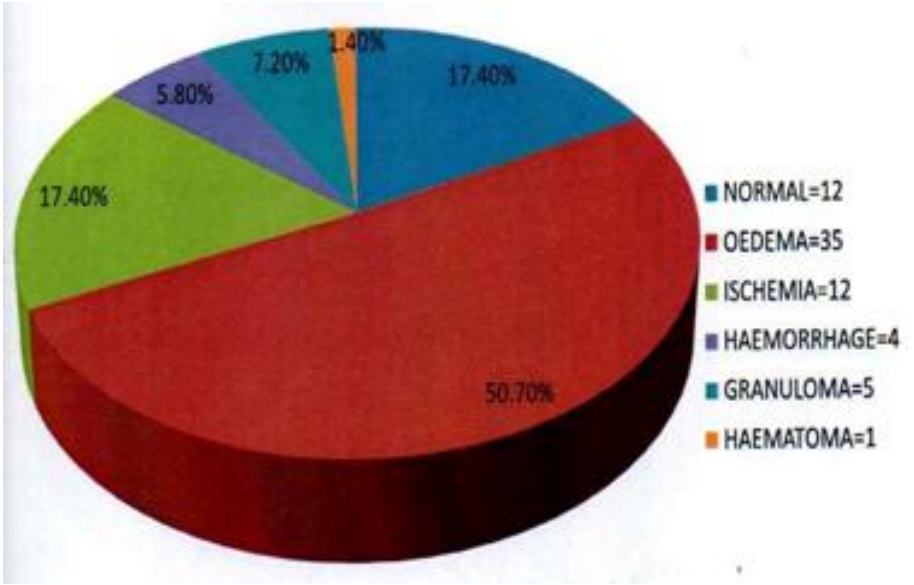

$17.4 \%$ (12/69) had no brain lesion; among the positive CT scan finding group (57/69), 50.7\% had brain edema, $17.4 \%$ with ischemia, $5.8 \%$ with hemorrhage, $7.2 \%$ with granuloma and $1.4 \%$ were with hematoma.

Figure 4: Distribution of study group according to brain lesion (Area)

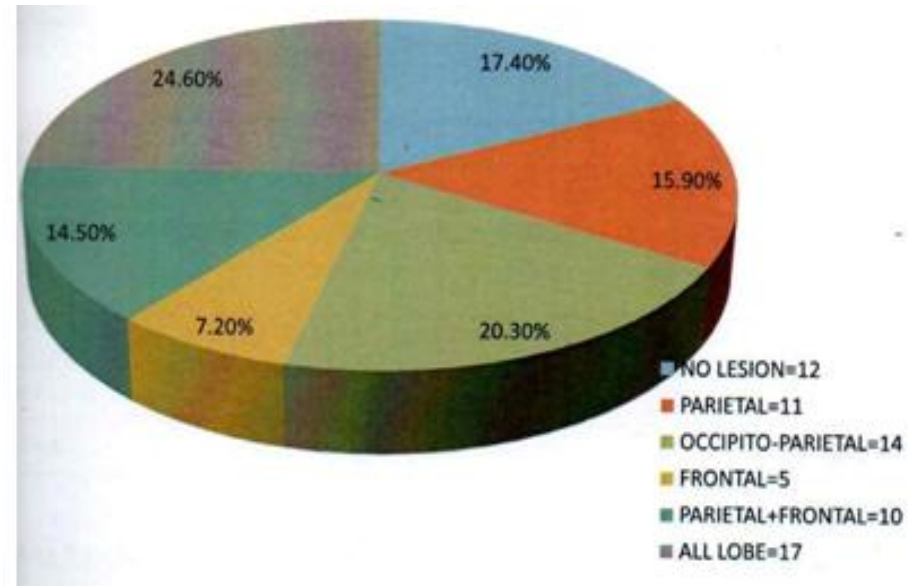

No lesion found in $17.4 \%$ of patients. Pure parietal and pure frontal lobe involvement found in $15.9 \%$ and $7.2 \%$ of patients respectively. Involvement of Occipito-parietal lobe were $20.3 \%$, fronto-parietal $14.4 \%$ and all lobe were $24.6 \%$. Interestingly, total parietal lobe involvement was 52 out of 69 patients, which is found to be $75.4 \%$. 
Table no -1. Brain lobe (Area) lesions in relation to CT scan findings

\begin{tabular}{|c|c|c|c|c|c|c|c|c|c|}
\hline \multicolumn{7}{|c|}{ CT scan findings of pathological lesion } & \multirow[b]{2}{*}{ Hematoma } & \multirow[t]{2}{*}{ Total } & $\mathrm{P}-$ \\
\hline \multirow{8}{*}{$\begin{array}{c}\text { Araes } \\
\text { of } \\
\text { brain } \\
\text { lesion }\end{array}$} & & Normal & Edema & Ischemia & Hemorrhage & Granuloma & & & \multirow{8}{*}{$\begin{array}{c}\text { p- } \\
\text { value } \\
0.000\end{array}$} \\
\hline & Normal & 12 & 0 & 0 & 0 & 0 & 0 & 12 & \\
\hline & Parietal & 0 & 5 & 4 & 0 & 2 & 0 & 11 & \\
\hline & Occipital +parietal & 0 & 7 & 6 & 1 & 0 & 0 & 14 & \\
\hline & Frontal & 0 & 4 & 0 & 0 & 1 & 0 & 5 & \\
\hline & Parietal+frontal & 0 & 7 & 0 & 2 & 1 & 0 & 10 & \\
\hline & All lobe & 0 & 12 & 2 & 1 & 1 & 1 & 17 & \\
\hline & Count & 12 & 35 & 12 & 4 & 5 & 1 & 69 & \\
\hline
\end{tabular}

The table shows the cross table relation between area of brain lesion (CT scan findings) and pathological brain lesion (CT scan finding). Here p- value is 0.000 , which is statistically highly significant.

Table 2: Vision in relation to brain lobe lesion (Area)

\begin{tabular}{|c|c|c|c|c|c|c|c|c|c|}
\hline & & \multicolumn{6}{|c|}{ Brain Lobe (Area) } & \multirow[t]{2}{*}{ Total } & \multirow{2}{*}{$\begin{array}{c}\mathrm{P} \\
\text { value }\end{array}$} \\
\hline & & Normal & Parietal & $\begin{array}{c}\text { Occipito+ } \\
\text { Parietal }\end{array}$ & Frontal & Parietal+Frontal & $\begin{array}{c}\text { All } \\
\text { Lobe }\end{array}$ & & \\
\hline \multirow[t]{4}{*}{ vision } & Normal & 9 & 8 & 8 & 4 & 8 & 4 & 41 & \multirow[t]{6}{*}{0.017} \\
\hline & $\%$ & $21.9 \%$ & $19.5 \%$ & $19.5 \%$ & $9.8 \%$ & $19.5 \%$ & $9.8 \%$ & $100 \%$ & \\
\hline & Disturb & 3 & 3 & 6 & 1 & 2 & 13 & 28 & \\
\hline & $\%$ & $10.7 \%$ & $10.7 \%$ & $21.4 \%$ & $3.6 \%$ & $7.1 \%$ & $46.4 \%$ & $100 \%$ & \\
\hline \multirow[t]{2}{*}{ total } & Count & 12 & 11 & 14 & 5 & 10 & 17 & 69 & \\
\hline & $\%$ & $17.4 \%$ & $15.9 \%$ & $20.3 \%$ & $7.2 \%$ & $14.5 \%$ & $24.6 \%$ & $100 \%$ & \\
\hline
\end{tabular}

Vision abnormality maximally noted in the occipito-parietal lobe and all lobe involvement $(6+13=19 / 28)$ and if we consider in cases of parietal lobe involvement, it is near about $85.6 \%$ $(10.7+21.4+7.1+46.4) ;(24 / 28)$. Here $p$ value is 0.017 and the value is statistically significant.

Table no 3 Types of eclampsia in relation with CT scan finding brain lesion

\begin{tabular}{|c|c|c|c|c|c|c|c|c|c|}
\hline & \multicolumn{8}{|c|}{ CT scan finding } & \multirow[b]{2}{*}{$\begin{array}{c}\mathrm{P} \\
\text { value }\end{array}$} \\
\hline & & normal & edema & ischemia & hemorrhage & granuloma & hematoma & total & \\
\hline \multirow{6}{*}{$\begin{array}{l}\text { Types of } \\
\text { eclampsia }\end{array}$} & Antepartum & 2 & 30 & 9 & 2 & 3 & 1 & 47 & \multirow{8}{*}{0.003} \\
\hline & $\%$ & $4.3 \%$ & $63.8 \%$ & $19.1 \%$ & $4.3 \%$ & $6.4 \%$ & $2.1 \%$ & $100 \%$ & \\
\hline & Intrapartum & 6 & 4 & 2 & 0 & 1 & 0 & 13 & \\
\hline & $\%$ & $46.1 \%$ & $30.8 \%$ & $15.4 \%$ & $0 \%$ & $7.7 \%$ & $0 \%$ & $100 \%$ & \\
\hline & Postpartum & 4 & 1 & 1 & 2 & 1 & 0 & 9 & \\
\hline & $\%$ & $44.4 \%$ & $11.1 \%$ & $11.1 \%$ & $22.2 \%$ & $11.1 \%$ & $0 \%$ & $100 \%$ & \\
\hline \multirow[t]{2}{*}{ total } & count & 12 & 35 & 12 & 4 & 5 & 1 & 69 & \\
\hline & $\%$ & $17.4 \%$ & $50.7 \%$ & $17.4 \%$ & $5.8 \%$ & $7.2 \%$ & $1.5 \%$ & $100 \%$ & \\
\hline
\end{tabular}

Only $4.3 \%$ (2/47) of antepartum eclampsia mother was with normal CT scan finding where as it was reverse during intrapartum $6 / 13 \quad(46.1 \%)$ and postpartum 4/9 (44.4\%) eclampsia. The $\mathrm{p}$ value is 0.003 which is statistically significant. 
Table no 4 Consciousness in relation to CT scan finding brain lesion

\begin{tabular}{|c|c|c|c|c|c|c|c|c|c|c|c|}
\hline \multirow{9}{*}{\multicolumn{2}{|c|}{$\begin{array}{l}\text { Level } \\
\text { of } \\
\text { consciousness }\end{array}$}} & \multicolumn{8}{|c|}{ CT scan finding } & \multirow[b]{2}{*}{ Total } & $\mathrm{P}$-value \\
\hline & & \multirow[b]{2}{*}{ Conscious } & Normal & Edema & \multicolumn{2}{|c|}{ Ischemia } & Hemorrhage & Granuloma & Hematoma & & \multirow{9}{*}{0.028} \\
\hline & & & 10 & 16 & \multicolumn{2}{|c|}{8} & 1 & 2 & 0 & 37 & \\
\hline & & & $27 \%$ & $43.2 \%$ & \multicolumn{2}{|c|}{$21.6 \%$} & $2.7 \%$ & $5.4 \%$ & $0 \%$ & $100 \%$ & \\
\hline & & Semiconscious & 0 & 7 & \multicolumn{2}{|c|}{0} & 2 & 0 & 1 & 10 & \\
\hline & & $\%$ & $0 \%$ & $70 \%$ & \multicolumn{2}{|c|}{$0 \%$} & $20 \%$ & $0 \%$ & $10 \%$ & $100 \%$ & \\
\hline & & Unconscious & 2 & 12 & \multicolumn{2}{|c|}{4} & 1 & 3 & 0 & 22 & \\
\hline & & $\%$ & $9.1 \%$ & $54.5 \%$ & \multicolumn{2}{|c|}{18.2} & $4.5 \%$ & $13.6 \%$ & $0 \%$ & $100 \%$ & \\
\hline & & Count & 12 & 35 & \multicolumn{2}{|c|}{12} & 4 & 5 & 1 & 69 & \\
\hline \begin{tabular}{c|c|c|c} 
Percentage & $17.4 \%$ & $50.7 \%$ & $17.4 \%$ \\
le relation between states of consciousness
\end{tabular} & & Percentage & $17.4 \%$ & $50.7 \%$ & \multicolumn{2}{|c|}{$17.4 \%$} & $5.8 \%$ & $7.2 \%$ & $1.5 \%$ & $100 \%$ & \\
\hline \multicolumn{12}{|c|}{$\begin{array}{l}\text { with pathological brain lesion. Here } 27 \%(10 / 37) \\
\text { patients showing normal CT scan finding in } \\
\text { conscious group as compared to semiconscious o\% } \\
(0 / 10) \text { and in unconscious } 9.1 \%(2 / 22) \text { group. } 30 \%\end{array}$} \\
\hline Table 1 & $5 \operatorname{Ran}$ & nge of GCS & lasgow & Coma Sc & ale) & rel & tion to $\mathrm{C}^{\prime}$ & scan finding 1 & ain lesion & & \\
\hline & & & & & & sca & finding & & & & \\
\hline & & Normal & Edema & Ischel & & & norrhage & Granuloma & Hematoma & Total & \\
\hline & $0-8$ & 0 & 0 & 0 & & & 0 & 1 & 1 & 2 & \\
\hline & $\%$ & $0 \%$ & $0 \%$ & $0 \%$ & & & $0 \%$ & $50 \%$ & $50 \%$ & $100 \%$ & P- \\
\hline & $9-12$ & 8 & 29 & 8 & & & 3 & 2 & 0 & 50 & value \\
\hline Range & $\%$ & $16 \%$ & $58 \%$ & $16 \%$ & & & $6 \%$ & $4 \%$ & $0 \%$ & $100 \%$ & 0.001 \\
\hline of GCS & $13-15$ & 4 & 6 & 4 & & & 1 & 2 & 0 & 17 & \\
\hline & $\%$ & $23.5 \%$ & $35.3 \%$ & 23.5 & & & $5.9 \%$ & $11.8 \%$ & $0 \%$ & $100 \%$ & \\
\hline & Count & 12 & 35 & 12 & & & 4 & 5 & 1 & 69 & \\
\hline \begin{tabular}{|l|} 
Total \\
\end{tabular} & $\%$ & $17.4 \%$ & $50.7 \%$ & 17.4 & & & $5.8 \%$ & $7.2 \%$ & $1.5 \%$ & $100 \%$ & \\
\hline
\end{tabular}

The table showing relation between ranges of GCS with pathological brain lesion. Here GCS 0-8 shows only 2 patients, one having granuloma and another one was with hematoma Maximum number of patients was showing GCS 9-12(50/69), among them $58 \%$ (29/50) of patients showed brain edema. The p-value is 0.001 , which is statistically highly significant.

Table no 6 Antenatal visit in relation to CT scan finding brain lesion

\begin{tabular}{|c|c|c|c|c|c|c|c|c|c|}
\hline \multicolumn{2}{|c|}{ Antenatal visit in relation to CT scan finding brain lesion } \\
\hline 01 & & Normal & Edema & Ischemia & Hemorrhage & Granuloma & Hematoma & Total & P-value \\
\hline & Booked & 12 & 26 & 07 & 01 & 04 & 01 & 51 & 0.048 \\
\hline & Percentage & $23.5 \%$ & $51 \%$ & $13.7 \%$ & $2 \%$ & $7.8 \%$ & $2 \%$ & $100 \%$ \\
\hline & Unbooked & 0 & 09 & 05 & 03 & 01 & 0 & 18 \\
\hline & Percentage & $0 \%$ & $50 \%$ & $27.8 \%$ & $16.7 \%$ & $5.5 \%$ & $0 \%$ & $100 \%$ \\
\hline & Count & 12 & 35 & 12 & 04 & 05 & 01 & 69 \\
\hline & Percentage & $17.4 \%$ & $50.7 \%$ & $17.4 \%$ & $5.8 \%$ & $7.2 \%$ & $1.5 \%$ & $100 \%$ & \\
\hline
\end{tabular}

The booked case means 4 or more antenatal visit. Here booked mother were $73.1 \%$ (51/69) and unbooked mother were 26.1(18/69) among the study group. The table shows the entire unbooked patient was with pathological brain lesions (normal
CT scan $=0)$. Here, more number of patients was presented with brain ischemia (27.8\%) and hemorrhage (16.7\%) as compared to booked patients. The p-value is 0.048 that is statistically significant 
Table no- 7 Extra dose of magnesium sulphate in relation to CT scan finding brain lesion

\begin{tabular}{|c|c|c|c|c|c|c|c|c|c|}
\hline & \multirow[b]{2}{*}{ Normal } & \multirow[b]{2}{*}{ Parietal } & \multirow[b]{2}{*}{$\begin{array}{l}\text { Occipito+ } \\
\text { parietal }\end{array}$} & \multirow[b]{2}{*}{ Frontal } & \multirow[b]{2}{*}{$\begin{array}{l}\text { Parietal+ } \\
\text { frontal }\end{array}$} & \multirow[b]{2}{*}{ All lobe } & \multirow{2}{*}{ Total } & \multirow{2}{*}{$\mathrm{P}$ value } \\
\hline & & & & & & & & & \\
\hline \multirow{4}{*}{$\begin{array}{l}\text { Extra } \\
\text { dose } \\
\text { of } \\
\mathrm{MgSo} 4\end{array}$} & Yes & 0 & 1 & 1 & 2 & 1 & 7 & 12 & \multirow{6}{*}{0.024} \\
\hline & $\%$ & $0 \%$ & $8.3 \%$ & $8.3 \%$ & $16.7 \%$ & $8.3 \%$ & $58.3 \%$ & $100 \%$ & \\
\hline & No & 12 & 10 & 13 & 3 & 9 & 10 & 57 & \\
\hline & $\%$ & $21.1 \%$ & $17.5 \%$ & $22.8 \%$ & $5.3 \%$ & $15.8 \%$ & $17.5 \%$ & $100 \%$ & \\
\hline \multirow[t]{2}{*}{ Total } & Count & 12 & 11 & 14 & 5 & 10 & 17 & 69 & \\
\hline & $\%$ & $17.4 \%$ & $15.9 \%$ & $20.6 \%$ & $7.2 \%$ & $14.5 \%$ & $24.6 \%$ & $100 \%$ & \\
\hline
\end{tabular}

The table showed that, for controlling repeated seizures, extra dose of $\mathrm{MgSo} 4$ was required in $17.4 \%(12 / 69)$ of patient and $82.6 \%$ (57/690 of patient controlled with normal regime.

\section{Discussion}

As previously mentioned, total 69 mothers were studied and computed tomography was performed as early as possible, within 72 hours. We did not conduct any follow up study or repeat CT scan among the study group. One (1.45\%) maternal death was recorded on day 6 of hospital stay after completion of CT scan due to multiorgan involvement and failure.

The mean age of study population was $19.59+/$ 2.046 years and maximum number of mother $(82.61 \%, 57 / 69)$ was in the age group of $17-20$ years. Only $4.35 \%(3 / 69)$ was above 25 years of age. So it may be assumed that early age of marriage and early child bearing could have been a factor for increased prevalence of eclampsia in this country $^{7}$. About 24.4\% (17/69) of patients were illiterate and only $28.99 \% \quad(20 / 69)$ were educationally qualified as matriculation to graduate. The mean systolic blood pressure was $160.39+/$ $14.826 \mathrm{~mm}$ of $\mathrm{Hg}$ and ranges were $140-200 \mathrm{~mm}$ of Hg. The mean diastolic blood pressure was $101.86+/-11.272 \mathrm{~mm}$ of $\mathrm{Hg}$ and ranges were 90$140 \mathrm{~mm}$ of $\mathrm{Hg}$.

Among the study population, primigravida was $81.16 \%$ (56/69). Second gravida was $11.60 \%(8 / 69)$ and the rest were multigravida, $7.25 \%(5 / 69)$ in comparison to a study conducted by $\mathrm{Y}$ Brouh et $\mathrm{al}^{8}$
(2016) where 67\% were primigravida in their study Gestational age up to 32 weeks was $17.39 \%$ (12/69), 33-36 weeks was 28.99\% (20/69), 37 weeks or above was $40.38 \%$ (28/69) and postpartum period was represented about $13.03 \%(9 / 69)$.

The maximum number of patients $(68.1 \%, 47 / 69)$ was with pedal edema $1+, 14.5 \%(10 / 69)$ showing pedal edema $2+$ and absence of pedal edema was $17.4 \%(12 / 69)$. With the help of Dipstick test, 23.19 $\%(16 / 69)$ having $1+$ proteinuria, $47.83 \%(33 / 69)$ having $2+, 23.19 \%(16 / 69)$ having $3+$ and $5.80 \%$ (4/69) having 4+ proteinuria.

In our study group, maximum number of mother delivered by caesarian section $(73.9 \%, 51 / 69)$ and vaginal delivery was performed only in 26.1(18/69). One stillbirth and 3 twin (all twin delivered by LSCS) babies were delivered. Total 72 babies were delivered, of which birth weight below $2 \mathrm{~kg}$ was $30.56 \%$ ( 22/72), $2 \mathrm{~kg}-2.49 \mathrm{~kg}$ was $33.33 \%$ ( 24/72) and $2.5 \mathrm{~kg}$ and above was $36.11 \%$ (26/72).

The CT scan finding of our study population shows $17.4 \%$ (12/69) have no brain lesion, 50.7\% (35/69) patient was with edema, $17.4 \%$ (12/69) with ischemia, $5.8 \%$ (4/69) with hemorrhage, $7.2 \%$ $(5 / 69)$ with granuloma and $1.4 \%$ (1/69) was with hematoma. Statistically highly significant $\mathrm{p}$ value (0.000) was observed in relation between area of brain lesion (CT scan findings) and pathological brain lesion (CT scan findings) (Table - 1).

Our study have some similarities with comparable study by Shamim Khandaker et $\mathrm{al}^{9}$, Begam $\mathrm{F}$ et $\mathrm{al}^{10}$, Harandou $\mathrm{M}$ et $\mathrm{al}^{11}$, Beye MD et $\mathrm{al}^{12}$ and Akan $\mathrm{H}$ et $\mathrm{al}^{13}$. 
Table no: 8 CT scan finding Brain Lesion in different study

\begin{tabular}{|l|c|c|c|c|c|}
\hline Studied by & normal & edema & Ischemia/infarction & Hemorrhage/hematoma & granuloma \\
\hline Our study & $17.4 \%$ & $50.7 \%$ & $17.4 \%$ & $7.2 \%$ & $7.2 \%$ \\
\hline Shamim Khandekar & $36.8 \%$ & $31.6 \%$ & $23.7 \%$ & $7.9 \%$ & ----- \\
\hline Begum F et al & $14.28 \%$ & $45.72 \%$ & $37.14 \%$ & $2.86 \%$ & ----- \\
\hline Harandou M et al & $15.79 \%$ & $73.68 \%$ & ------ & $10.52 \%$ & ---- \\
\hline Beye MD et al & ----- & ----- & ----- & $14.29 \%$ & ----- \\
\hline Akan H et al & $18.18 \%$ & $50 \%$ & $13.63 \%$ & $9.09 \%$ & ---- \\
\hline
\end{tabular}

In the study population, $40.6 \%$ (28/69) of eclampsia mother was presented with visual disturbance in the form of dimness of vision, blurring of vision or even unilateral or bilateral loss of vision. In $59.4 \%$ (41/69) of cases there is no abnormality of vision. Majority of them (15/28) showing brain edema (53.6\%) who had visual disturbance and in $10.7 \%$ $(3 / 28)$ of patient, there is no pathological lesion on CT scan. Visual abnormality maximally noted in the occipito-parietal lobe and all lobe involvement patients $(6+13=19 / 28)$. If we consider about parietal lobe involvement, it is near about $85.6 \%$ $(10.7+21.4+7.1+46.4=85.6) ;(24 / 28)$. Here $p$ value is 0.017 and the value is statistically significant. (table no 2)

Only $4.3 \%(2 / 47)$ of antenatal mother was with normal CT scan findings whereas it is reverse in intrapartum (6/13) $46.1 \%$ and $44.4 \%$ (4/9) in postpartum eclampsia. It means ante partum eclampsia showing more abnormal CT scan finding than the other two varieties with a significant $p$ value 0.003.(Table no 3 )

Among the study group, 22/69 (31.89\%) patient was having history of unconsciousness, $10 / 69$ (14.50\%) was semiconscious and 37/69 (53.62\%) was without any history of unconsciousness during the event of convulsion. About 27\% (10/37) patient was showing normal $\mathrm{CT}$ scan finding in conscious group as compare to semiconscious $0 \%(0 / 10)$ and in unconscious $9.1 \%(2 / 22)$ group. $30 \%$ (3/10) patients were showing hemorrhage and hematoma in semiconscious group and $13.6 \%(3 / 22)$ was with granuloma in unconscious group. The $\mathrm{p}$ value is 0.028 and that is statistically significant (table no 4).
According to severity of patient's condition, we categorized GCS (Glasgow Coma Scale) gradation; GCS $0-8=2.90 \% \quad(2 / 69)$ was very severe neurological impairment, GCS $9-12=72.46 \%$ (50/69) was moderate, GCS 13 and above $=24.64 \%$ (17/69) had no impairment. GCS 0-8 shows only 2 patients (2/69), one of them was having granuloma and another one was with hematoma. Maximum number of patients was showing GCS 9-12 (50/69), among them $58 \%(29 / 50)$ of patient showed brain edema. The table showing $\mathrm{p}$ value is 0.001 .which is statistically highly significant (table no 5). Beye MD et $\mathrm{al}^{12}$. (2003) described mean GCS was $8+\mid-2$ in their study.

The booked mother indicating those who attended 4 or more antenatal visit. Booked mother was $73.1 \%$ ( $51 / 69)$ and unbooked was $26.1 \%$ (18/69) among the study group. The entire unbooked patient was with pathological brain lesion (normal CT scan was 0\%). More number of patients was presented with brain ischemia (27.8\%) and hemorrhage (16.7\%) as compared to booked patients. The $\mathrm{p}$ value is 0.048 that is statistically significant (table no-6).

For controlling repeated seizures, extra dose of MgSo4 was required in $17.4 \%$ (12/69) of patient and $82.6 \%(57 / 690$ of patient controlled with normal regime. $\mathrm{MgSo} 4$ requirement was significantly increased in patients presented with hemorrhage, granuloma and hematoma. About $58.3 \%$ (7/12) of patient were showing all lobe involvement where extra dose $\mathrm{MgSo} 4$ was given and $\mathrm{p}$ value is 0.024 , that is also statistically significant. (Table no-7) 


\section{Conclusion}

It has observed that during ante partum eclampsia, pathological brain lesions and brain lobe lesions were much more predominant as compared to intrapartum and postpartum eclampsia. There was positive correlation between occipito-parietal lobe involvement and visual abnormality. Moreover, CT scan found that entire unbooked patient group was with pathological brain lesion (normal CT scan=0) than the booked group. Almost one third patients have normal CT scan in conscious group compared to $0 \%$ in semiconscious and $9 \%$ in unconscious group with significant $p$ value. The mean GCS is 11.22 and those with 8 or less, have pathological brain lesion. Regarding loading dose of $\mathrm{MgSO} 4$, requirement significantly increased in patients having cerebral hemorrhage, granuloma and hematoma. If CT finding consistent with cerebral hemorrhage, subdural hematoma or granuloma, there might be requirement of multidisciplinary approach with the help of other super specialties. CT scan thus can be a preferred guide to diagnose and detect other co-existing brain lesions and thus reducing maternal morbidity and mortality.

\section{Bibliography}

1. Marilyn J. Cipolla,PhD and Richard P. Kraig, $\mathrm{MD}, \mathrm{PhD}$. Seizures in women with eclampsia: Mechanisms and Management: Fetal Matern Med Rev.2011 May;22(02):91-108.

2. DC Dutta's Text book of obstetrics; Edited by Hiralal Konar, seventh edition.

3. Y Brouh, Konan Kouassi Jean, A Ouattara et.al. Brain lesions in eclampsia: A series of 39 cases admitted in an Intensive Care Unit: Indian J Crit Care Med 2016;20:178-81; Year :2016|volume20|Issue:3|page 178-181.

4. Williams Obstetrics, $24^{\text {th }}$ Edition.

5. Demirtas O, Gelal F, Vidinil BD et al. Cranial MR imaging with clinical correlation in preeclampsia \& eclampsia. Diagn Interv Radiol 2005,11:189-94:PubMed Google Scholar.

6. Schwartz RB,Feske SK, Polak JF,et al.PE-E clinical \& neuro-radiographic correlates and insights into the pathogenesis of hypertensive encephalopathy. Radiology2000;217;37176.Ref PubMed Google Scholar.

7. Socio- Demographic and other risk factors of preeclampsia at a tertiary care hospital, Karnataka: case control study; Ramesh K, Sangeetha Gandhi. Rao; JCDR, july,2014.

8. Y Brouh, Konan Kouassi Jean, A Quattara, Y Tetchi, Y Pete, N Koffi, C Abhe, M Kane; Brain lesions in eclampsia: A series of 39 cases admitted in an intensive care unit: Indian J Crit Care Med 2016;20:178-81,vol-20;Issue 3.

9. Shamim Khandekar, Madhusudan Halder and Shabana Munshi; Intra cerebral changes detected by CTscan of brain in Eclampsia: Austin J Obstet Gynecol: vol-1,issue 3,2014.

10. Begum FI, Nahar K, Ahmed MU, Ferdousi RA et al.-Study on neurological manifestation of eclampsia and finding of CT scan of brain: Mymensingh Med J 2015 Oct;24(4): 691-6.

11. Harandou M, Madani N, Labibe S. et al: Neuroimaging findings in eclamptic patients still symptomatic after 24 hours: a descriptive study about 19 cases: Annales Francaises D'anesthesie et de Reanimation [2006, 25(6):577-583]

12. Akan H, Kucuk M, Bolat O, Selcuk MB, Tunali G: The diagnostic value of cranial computed tomography in complicated eclampsia: J Belge Radiol,1993Oct ;76(5):3046.

13. Beye MD, Diouf E, Kane O, Ndoye MD, Seydi A, Ndiaye PI, Sall BK; Intensive care management of 28 patients with severe eclampsia in a tropical African setting: Annales Francaises D'anesthesie et de Reanimation [2003,22(1):25-29]. 